\title{
UM OLHAR REFLEXIVO PARA O USO E APLICABILIDADE DA TECNOLOGIA ASSISTIVA NA EDUCAÇÃO MATEMÁTICA1 ${ }^{1}$
}

\author{
Maria Inêz Vasconcelos da Silva \\ Faculdade de Engenharia - FEIS/UNESP - Campus de Ilha Solteira \\ inezvasconcelos_4.0@hotmail.com \\ Andrezza Santos Flores \\ Faculdade de Ciências - FC/UNESP - Campus de Bauru \\ andrezzaflores6@gmail.com
}

\begin{abstract}
RESUMO
O contexto educacional contemporâneo vislumbra novas e complexas demandas frente ao paradigma da inclusão escolar, quanto ao uso e aplicabilidade das tecnologias, e isso implica a reestruturação do processo de ensino e aprendizagem em todas as áreas do conhecimento. Nesta reflexão crítica, trataremos do ensino e aprendizagem da matemática, visto que com as novas determinações de uma educação para todos, torna-se fundamental a eliminação de barreiras escolares que impedem os estudantes público-alvo da educação especial, a ter acesso ao currículo. A educação especial e inclusiva traz em suas estratégias de ação, a tecnologia assistiva para construção de conceitos procedimentais e atitudinais, de forma pontual, concreta e acessível, para que docentes desenvolvam habilidades na resolução de problemas em geral e auxilie no acesso e na resolução de desafios matemáticos, melhorando a prática docente para que os estudantes público-alvo da Educação Especial não sejam excluídos das aulas de matemática. Portanto, o presente trabalho busca contribuir para a compreensão do conceito de tecnologia assistiva, principalmente no contexto da educação especial, atrelado a importância da articulação/interlocução dos constituintes do sistema educacional, seja equipe gestora, professor da sala de recursos, ensino regular e demais redes de apoio, perpassando na Educação Matemática e tendo como esteio a Base Nacional Comum Curricular (BNCC) na construção de uma nova cultura profissional.
\end{abstract}

Palavras-chave: Educação Especial. Educação Matemática. Tecnologia Assistiva.

\section{A REFLECTIVE LOOK AT THE USE AND APPLICABILITY OF ASSISTANT TECHNOLOGY IN MATHEMATICAL EDUCATION}

\begin{abstract}
The contemporary educational context envisions new and complex demands regarding the paradigm of school inclusion, regarding the use and applicability of technologies,

${ }^{1}$ Este artigo é a versão expandida de uma comunicação oral apresentada no VII Simpósio de Educação Inclusiva e Adaptações/ V Simpósio Internacional de Educação a Distância. São Paulo, UNESP, 2019.
\end{abstract}


and this implies the restructuring of the teaching and learning process in all areas of knowledge. In this critical reflection we will deal with the teaching and learning of mathematics since, with the new determinations of education for all, it is essential to eliminate school barriers that prevent students from special education to have access to the curriculum. Special and inclusive education brings in its action strategies, assistive technology for the construction of procedural and attitudinal concepts, in a timely, concrete and accessible way, so that teachers develop skills in solving problems in general and assist in accessing and solving problems and mathematical challenges, improving teaching practice, so that the target public students of Special Education are not excluded from math classes. Therefore, the present work seeks to contribute to the understanding of the concept of assistive technology, especially in the context of special education, linked to the importance of articulation/dialogue between the constituents of the educational system, namely, the management team, resource room teacher, regular education and others support networks, participating in mathematical education and having as mainstay the Common National Curriculum Base (BNCC) in the construction of a new professional culture.

Keyword: Special education. Mathematical education. Assistive Technology.

\section{UNA MIRADA REFLEXIVA AL USO Y APLICABILIDAD DE LA TECNOLOGÍA DE ASISTENCIA EN LA EDUCACIÓN MATEMÁTICA}

\section{RESUMEN}

El contexto educativo contemporáneo ve demandas nuevas y complejas frente al paradigma de inclusión escolar, con respecto al uso y la aplicabilidad de las tecnologías, y esto implica la reestructuración del proceso de enseñanza y aprendizaje en todas las áreas del conocimiento. En esta reflexión crítica abordaremos la enseñanza y el aprendizaje de las matemáticas, ya que con las nuevas determinaciones de una educación para todos, es esencial eliminar las barreras escolares que impiden que los estudiantes de la educación especial, tengan acceso al currículo. La educación especial e inclusiva trae en sus estrategias de acción tecnología de asistencia para la construcción de conceptos procesales y de actitud, de una manera específica, concreta y accesible, para que los maestros desarrollen habilidades para resolver problemas en general y ayuden a acceder y resolver problemas y desafíos matemáticos, mejorar la práctica docente, de modo que los estudiantes que se dirigen a Educación Especial no sean excluidos de las clases de matemáticas. Por lo tanto, este documento busca contribuir a la comprensión del concepto de tecnología de asistencia, especialmente 
en el contexto de la educación especial, vinculado a la importancia de la articulación/ diálogo entre los constituyentes del sistema educativo, ya sea un equipo directivo, un maestro en la sala de recursos, educación regular y otros redes de apoyo, a través de la Educación Matemática y teniendo como base la Base Curricular Común Nacional (BNCC) en la construcción de una nueva cultura profesional.

Palabras clave: Educación Especial. Educación Matemática. Tecnología de asistencia.

\section{INTRODUÇÃO}

Mantoan (2006) destaca que vivemos um tempo de crise global, em que velhos paradigmas da modernidade estão sendo contestados e em que o conhecimento, matéria-prima da educação escolar, passa por uma reinterpretação. A inclusão é parte dessa constatação e implica também numa mudança no perfil do atendimento nos setores públicos, principalmente no que tange os setores educacionais. $O$ uso de tecnologias nas relações sociais é uma exigência mundial, pois o seu poder de alcance digital, o manuseio de dados, ampliação de possibilidades, o envolvimento e a rapidez nas comunicações permitem a globalização de ideias e o compartilhamento de saberes.

Posto isto, a escola se destaca como uma microestrutura dentro desse grande universo interacional, ela precisa estar aberta à diversidade, respeitando, assim, as determinações de um contexto democrático, especial e inclusivo; supõem neste sentido, inúmeras transformações em diversos setores do contexto escolar. É um grande desafio atitudinal, arquitetônico, metodológico e pedagógico que requer desconstrução de valores e ações tradicionais enraizadas (MANTOAN, 2006).

Ponte (2014) enfatiza a formação inicial e a formação continuada, pois os professores precisam acompanhar as mudanças sociais que se estabelecem e se refazem constantemente no interior das escolas: "os professores devem ser encorajados a trocar experiências inclusivas com outros colegas e a envolver-se na realização de projetos coletivos para a transformação das condições do ensino e aprendizagem" (PONTE, 2014, p. 353).

É sabido que não é uma tarefa fácil utilizar as tecnologias digitais no contexto escolar, pois geralmente as escolas não estão adequadas estruturalmente; quando têm salas com computadores obsoletos; outras vezes não há manutenção adequada (tanto para a máquina quanto nas atualizações de software). Porém, "se o professor não tiver espaço para refletir sobre as mudanças que acarretam a presença da informática [...], eles tenderão a não utilizar essas mídias, ou a utilizá-las de maneira superficial" (BORBA; PENTEADO, 2010, p. 88-89). 
Os desafios para a concretização dos ideais inclusivos na educação brasileira são inúmeros. Além dos que são impostos pela organização excludente das nossas escolas, temos de vencer o conservadorismo das instituições especializadas e enfrentar as pressões políticas e das pessoas com deficiência, que ainda estão muito habituadas a viver de seus rótulos e de benefícios que acentuam a incapacidade, a limitação, o paternalismo e o protecionismo social. (MANTOAN, 2010, p. 17).

No entanto, é fundamental esclarecer que, quando falamos de tecnologia, não estamos nos referindo somente às Tecnologias Digitais. É preciso considerar que se trata de toda e qualquer ferramenta que pode ser usada na eliminação de barreiras atitudinais, arquitetônicas, procedimentais, metodológicas, pedagógicas e clínicas, bem como a área da saúde em prol da qualidade de acesso, garantindo assim uma participação consciente, digna e protagonista dos estudantes com deficiência, transtorno global do desenvolvimento e com alta habilidade.

Portanto, o presente trabalho busca contribuir para a compreensão do conceito de tecnologia assistiva, principalmente no contexto da educação especial, atrelado a importância da articulação/interlocução dos constituintes do sistema educacional, seja equipe gestora, professor da sala de recursos, ensino regular e demais redes de apoio da área da saúde, perpassando na Educação Matemática e, tendo como esteio, a Base Nacional Comum Curricular (BRASIL, 2017) e a nova propositura de um Currículo Paulista na construção de uma nova cultura profissional.

\section{BREVE HISTÓRICO DAS PESSOAS COM DEFICIÊNCIA}

Antes mesmo de falarmos numa inclusão social é preciso voltar nos primórdios da história e nos reportarmos à exclusão social. Na história da humanidade, a pessoa com algum tipo de deficiência sempre foi envolta a situações pejorativas e de marginalização no qual essas pessoas eram completamente excluídas como um tipo de presságio negativo, de ineficiência e de invisibilidade.

Nesse sentido, ter uma pessoa com deficiência era uma tragédia e no decorrer da história houve três maneiras de se compreender a deficiência: o modelo da prescindência, onde a deficiência estava ligada à natureza religiosa, pois a deficiência advinha dos pecados dos pais, de sessões de feitiçaria, magia negra e cultos diabólicos, os que sobreviviam eram sujeitados a todo tipo de barbárie e degradação social. Sob essa compreensão, muitas comunidades primitivas praticaram o infanticídio de crianças cegas ou acometidas por alguma deficiência (AMARAL, 1994).

No decorrer da história, os espartanos contavam com a decisão dos anciãos para a preserาvação ou não da vida do recém-nascido acometido de deficiência. Sabe-se também que em "Atenas era permitido o infanticídio daqueles que nasciam débeis ou com alguma deformidade". (PALACIOS, 2008, p.42). A Lei das 
Doze Tábuas, precisamente na Tábua Quarta, permitia ao pai matar o filho nascido disforme, mediante o julgamento de cinco vizinhos. Roma manteve o infanticídio nessas circunstâncias até o ano II d.C. essa situação de eugenia perdurou até meados do século XX. A Alemanha nazista defendeu ideias eugênicas, buscando a qualidade da raça até por meio de medidas de esterilização populacional. Outras nações também ad $\neg$ mitiram a esterilização de grupos humanos para fins eugênicos, sejam elas a Suíça, a Dinamarca, a Suécia e a Noruega.

Após a II Guerra Mundial, devido à demanda de soldados amputados, há uma busca de garantir os direitos fundamentais, os deficientes derivados das guerras conseguiam se aposentar por invalidez, já os demais como nunca contribuíram para uma previdência, ficavam sujeitos à caridade das igrejas, instituições assistenciais e, até mesmo, de hospitais que ainda funcionavam como moldes de exclusão e violência.

Diante de tantas discussões sociais, são promulgadas diversas legislações pertinentes aos direitos fundamentais: Declaração dos Direitos Humanos/ONU (1948), Declaração de Goten: Educação para todos (1990), Resolução/ONU 48/96: Normas de Equiparação de Oportunidades (1993) Declaração de Salamanca/ONU: Princípios, políticas e práticas educacionais na educação especial (1994), Declaração de Guatemala/ONU: Eliminação de todas as formas de Discriminação (1999) e, dessas declarações e convenções, derivam-se muitas outras que objetivam oportunizar o acesso desse público a qualquer setor da vida social.

ALei n. ${ }^{\circ} 6.179$ que instituiu a Lei Orgânica da Previdência Social estabeleceu a aposentadoria por invalidez (renda mensal vitalícia aos inválidos não contribuintes da previdência). Considerava, para esse fim, inválida a pessoa definitivamente incapacitada para o trabalho que também não auferia renda por outro meio. A prova da invalidez se fazia por exame perante a própria previdência social urbana ou rural. A partir de 1993, a Lei $n^{\circ}$. 8.742, que institui a Lei Orgânica da Assistência Social, informa entre os objetivos da assistência social, a habilitação e reabilitação das pessoas com deficiência e a promoção de sua integração à vida comunitária. Para esta lei, considera-se pessoa com deficiência, "aquela que tem impedimento de longo prazo de natureza física, mental, intelectual ou sensorial, o qual, em interação com uma ou mais barreiras, pode obstruir sua participação plena e efetiva na socieda $\urcorner$ de em igualdade de condições com as demais pessoas" (art. 20, parágrafo II).

\section{AS IDEIAS EUGÊNICAS NO BRASIL}

Com o advento da contemporaneidade muda-se a abordagem do atendimento das pessoas com deficiência, surgindo assim o modelo médico que retirou a causa da deficiência como algo derivado do pecado, do obscuro, e dando um caráter científico, ou seja, através de estudos buscou-se identificar os aspectos 
naturais ou biológicos das deficiências. Nesta época, também surgem às ciências sociais para abordar as mazelas advindas da modernidade e pós-modernidade que causaram epidemias, pobreza, desemprego, amputados de guerra, loucos/doentes mentais, marginalizados sociais e pessoas com deficiência.

Surge, assim, a Sociologia e os serviços de assistências a essas pessoas marginalizadas e também à pessoa com deficiência, pois eram pessoas que não deveriam ser vistas como um objeto inútil, mas como alguém que neces $\neg$ sita da comunidade para favorecer a sua reabilitação ou normalização, notadamente com o auxílio dos recursos disponibilizados pela medicina, recaindo no paternalismo e em um assistencialismo sistemático, pois ainda as pessoas com deficiência eram tidas como improdutivas e incapazes de se manterem socialmente.

O modelo social surgiu para enfatizar que, muitas vezes, as pessoas com deficiência não têm eficiência acadêmica ou profissional por impedimento procedimental, arquitetônico e quase sempre atitudinal devido enfatizarem a deficiência e não as potencialidades que a pessoa possui e assim julgam preconceituosamente e não oportunizam sua participação. Palacios (2008, p.104) afirma que grande parte das dificuldades enfrentadas pelas pessoas com deficiência é atribuída às barreiras socialmente instituídas, se aposta na reabilitação da sociedade para favorecer a inclusão.

Vivemos num país excludente que, desde o seu surgimento as relações foram marcadas por exploração, marginalização, domesticação e, sucessivamente, a exclusão social. E a escola, enquanto parte deste macrossocial surge com um grande laboratório interacional, onde nas relações de troca e discussão tem como um de seus objetivos empoderar os sujeitos para que sejam protagonistas e transformadores sociais.

\footnotetext{
Art. $5^{\circ}$ Todos são iguais perante a lei, sem distinção de qualquer natureza, garantindo-se aos brasileiros e aos estrangeiros residentes no País a inviolabilidade do direito à vida, à liberdade, à igualdade, à segurança e à propriedade, nos termos seguintes... XLI - a lei punirá qualquer discriminação atentatória dos direitos e liberdades fundamentais. (BRASIL, 1988).
}

O Brasil, enquanto signatário de toda essa propositura em prol de uma sociedade inclusiva, postulou Convenções, a Lei n. ${ }^{\circ} 4.969 / 2009$ e, recentemente, aprovou o Estatuto da Pessoa com Deficiência com a Lei n. ${ }^{\circ} 13.146 / 2015$, que traz em suas linhas um caráter jurídico de diversos direitos da pessoa com deficiência. Há também cartilhas de orientação para todos os setores públicos e em especial aos promotores de todo o Brasil quanto à observância e garantia dos direitos das pessoas com deficiência.

Dado isto, a educação, desde que foi criada, esteve a serviço de uma política capitalista de exploração dos menos favorecidos. Paulo Freire (1993) tentou enfatizar o caráter transformador das escolas, porém sabe-se que nossas ações sociais e escolares, mesmo que inconscientes, continuam mantendo o status quo. 
Para que haja uma transformação social é necessário compreender e aceitar o outro em suas diferenças, proporcionando um ambiente que favoreça o desenvolvimento de todos. É preciso entender que incluir não é meramente matricular um estudante em um ambiente escolar e considerar que ele esteja realmente incluído. Ele até poderá estar inserido, mas para a inclusão acontecer realmente, passa por processos bastante complexos, desafiantes, que dependem de cada sujeito que compõe a equipe escolar.

O Sistema educacional precisa rever seus conceitos, necessita construir novos saberes; se adequando as novas exigências de uma sociedade democrática e aberta à diversidade, pois a inclusão tem que sair do papel, deve ser assumida com responsabilidade, em qualquer espaço social. A Política Nacional de Educação na Perspectiva da Educação Especial e Inclusiva traz em seus marcos teóricos e políticos a Educação Especial como modalidade de ensino que perpassa todos os níveis de escolarização.

O Brasil participou da Convenção sobre os Direitos das Pessoas com Deficiência (ONU/2006), promulgando por meio do Decreto n. ${ }^{\circ} 6.949 / 09$, assumindo o compromisso de assegurar o acesso das pessoas com deficiência e com Necessidades Educacionais Especiais a um sistema educacional inclusivo em todas as modalidades e níveis, adotando medidas que garantissem as condições para sua efetiva participação, de forma que os estudantes não sejam excluídos do sistema educacional em razão de sua deficiência ou de suas dificuldades sociais, econômicas, raciais, culturais, clínicas e de aprendizagem.

No artigo 58 da LDBEN (1996), parágrafo $1^{\circ}$, haverá, quando necessário, serviços de apoio especializado, na escola regular, para atender às peculiaridades da clientela de educação especial. No contexto das políticas públicas fica evidente a importância das Redes de Apoio junto à Educação Inclusiva para articulação de informações e serviços para o atendimento às especificidades dos estudantes públicoalvo da Educação Especial e Inclusiva, matriculados no ensino regular em qualquer nível de escolarização.

\section{A BASE NACIONAL COMUM CURRICULAR (BNCC) E O DESENVOLVIMENTO DE COMPETÊNCIAS DIGITAIS}

A Base Nacional Comum Curricular (BNCC) surge como importante documento de caráter normativo que define e norteia o conjunto orgânico e progressivo de aprendizagens essenciais que todos os estudantes devem desenvolver ao longo das etapas e modalidades da Educação Básica subsidiada por princípios éticos, políticos e estéticos estabelecidos pela Política Nacional da Educação na Perspectiva da Educação Especial e Inclusiva e pela Lei de Diretrizes e Bases (LDB n 9.394/96) 
para a formação humana integral em prol de uma sociedade mais justa, democrática e inclusiva (BRASIL, 1996, 2017).

A correlação entre o letramento matemático e o uso das tecnologias/ tecnologias digitais decorre do desenvolvimento integral, salientado pela BNCC como as habilidades de raciocinar, representar, comunicar e argumentar matematicamente de modo a favorecer o estabelecimento de conjecturas, a formulação e a resolução de problemas, forma significativa e contextualizada, reconhecendo, assim, o caráter inclusivo quanto ao uso das tecnologias na construção efetiva e concreta na compreensão e a atuação no mundo e perceber o caráter de jogo intelectual da matemática, como aspecto que favorece o desenvolvimento do raciocínio lógico e crítico, estimula a investigação e pode ser prazeroso para todos os estudantes e principalmente para os estudantes público-alvo da educação especial (BRASIL, 2017).

Já a Constituição Federal de 1988 traz, em seu Art. 208, que é o dever do Estado com a educação será efetivado mediante a garantia de: III - atendimento educacional especializado aos estudantes com deficiência, preferencialmente na rede regular de ensino (BRASIL, 1988).

ABNCC em suas linhas destaca 10 competências que auxiliam na formação acadêmica (conceitual e atitudinal) e na construção de habilidades (procedimentais) do estudante desde o Ensino Infantil até o Ensino Médio, entre elas, destacamos 05 (cinco) competências que estão correlatas ao uso de tecnologia: Conhecimento, Pensamento Científico, Crítico e Criativo, Repertório Cultural, Comunicação, Cultura digital, buscando sempre contextualizar e dar significado aos desafios interdisciplinares (BRASIL, 2017).

Essas cinco competências apresentam-se interligadasao uso eaplicabilidade das tecnologias enquanto ferramentas pedagógicas que podem facilitar o acesso e a aprendizagem e, até mesmo, eliminar barreiras que impedem os estudantes público alvo da educação especial e inclusiva de terem acesso ao currículo (BRASIL, 2017).

Cabe destacar que a BNCC não faz referência direta à tecnologia assistiva, mas por analogia podemos interpretar que o uso das tecnologias e principalmente das tecnologias digitais são fundamentais para o desenvolvimento integral do estudante público alvo da educação especial, onde diz que é preciso reconhecer a necessidade de práticas pedagógicas inclusivas e de diferenciação curricular aos estudantes com deficiência, ou seja, não é um currículo a parte, mas sim um tempo maior de realização das atividades e estratégias/recursos que corroborem com o aprendizado significativo e contextualizado.

Sendo assim, essa facilidade ou possibilidade de acesso à vida, à sociedade e, sucessivamente, à educação é que nos incentiva a busca constante de produção científica, formação continuada e aperfeiçoamento profissional, pois a tecnologia assistiva surge como uma área do conhecimento com características 
interdisciplinares, pois a somatória de ações multiprofissionais e seus olhares técnicos frente às limitações sociais, físicas, sensoriais e intelectuais proporcionam ajudas técnicas pontuais, e essas ajudas maximizam a aprendizagem individual e, num olhar geral, maximiza a aprendizagem de todos.

Com relação ao termo "assistiva", não há uma definição conceitual em dicionário da palavra, porém é um termo utilizado em outros países como sinônimo de "ajudas técnicas", pois deriva da palavra assistir que quer dizer ajudar, auxiliar.

Segundo Bersch (2006), Tecnologia Assistiva é um termo ainda novo, utilizado para identificar todo o arsenal de recursos e serviços que contribuem para proporcionar ou ampliar habilidades funcionais de pessoas com deficiência e, consequentemente, promover vida independente e inclusão. "A Tecnologia Assistiva deve ser entendida como um auxílio que promoverá a ampliação de uma habilidade funcional deficitária ou possibilitará a realização da função desejada e que se encontra impedida por circunstância de deficiência ou pelo envelhecimento" (BERSCH, 2017, p. 2).

Diante da conceituação do que é tecnologia assistiva, para lidar com as incertezas trazidas por essas mudanças, é necessário um amplo trabalho de reflexão coletiva e uma interlocução do trabalho docente da sala regular e o professor especialista da sala de recursos multifuncionais quanto ao atendimento educacional especializado (AEE). "Para as pessoas sem deficiência, a tecnologia torna as coisas mais fáceis. Para as pessoas com deficiência, a tecnologia torna as coisas possíveis" (RADABAUGH, 1993).

Os gestores e coordenadores precisam atuar na abertura e na manutenção das salas de recursos multifuncionais (SRMs), numa busca constante de recursos humanos, técnicos/especializados e de apoio pedagógico. Além disso, é fundamental também atuar nas parcerias com redes de apoio tais como: saúde (médicos, fonoaudiólogos, psicólogos, fisioterapeuta, terapeuta ocupacional etc.), transporte, assistência social etc., para o atendimento às especificidades dos estudantes públicoalvo da educação especial (EPAEE), matriculados no ensino regular.

Podemos então dizer que o objetivo maior da Tecnologia Assistiva é proporcionar à pessoa com deficiência maior independência, qualidade de vida e inclusão social, através da ampliação de sua comunicação, autonomia e participação social.

\section{INTERSECÇÃO ENTRE A EdUCAÇÃO MATEMÁTICA E O USO DE TECNOLOGIA ASSISTIVA}

Neste artigo, de cunho teórico, podemos perceber o quão importante é o uso das Tecnologias Assistivas na mediação entre o saber (teoria) e a construção de habilidades (prática) no ensino e aprendizagem da Educação Matemática, como mencionado por Bicudo (1993) ao nos chamar a atenção para que a: 
[...] pesquisa em Educação Matemática vale. Ela permite que se compreenda a Matemática, o modo pelo qual ela é construída, os significados da Matemática no mundo. Com isso, ela presta serviço à Educação e à Matemática. À Matemática, por ajudá-la a compreender-se. À Educação, por auxiliar a ação político-pedagógica. (BICUDO, 1993, p. 22).

Há mais de três décadas, a Educação Matemática vem se consolidando internacionalmente enquanto área de pesquisa. Segundo Bicudo (1993), a Educação Matemática se preocupa com o fazer Matemática, com o compreender a Matemática, com interpretações sobre significados culturais, históricos e sociais da Matemática, bem como as ações político-pedagógicas em seu entorno. "São, portanto, pesquisas que solicitam domínio compreensivo de um vasto horizonte de conhecimentos, como os horizontes da Psicologia, da História, da Filosofia [...]" (BICUDO, 1993, p. 20).

Javaroni e Zampieri (2015) corroboram ao destacar que, na sociedade contemporânea, o uso das tecnologias se faz presente em diversos momentos do cotidiano. Em contrapartida, ao lançarmos nosso olhar no sistema educacional, mais especificamente aulas de Matemática, a presença das tecnologias nem sempre acontece.

No entanto, as autoras evidenciam que os debates referentes aos processos de ensino e aprendizagem atrelando a matemática e suas tecnologias vêm se expandindo mediante ao fomento na formação inicial e continuidade dos professores.

\footnotetext{
Apesar dessas possíveis dificuldades, os autores ressaltam a importância de que o professor enfrente suas zonas de risco para promover mudanças em suas práticas, em particular o professor de Matemática. Em contrapartida, eles pontuam que esse não é o caminho mais fácil a ser tomado, e sim, talvez, o mais árduo. Nesse sentido, eles argumentam que o professor avança pouco para essa zona, saindo de seu conforto, se ele não reflete acerca disso com outras pessoas, sejam professores e/ou pesquisadores. Diante disso, 'é necessário encontrar formas de oferecer um suporte constante para o trabalho do professor'. (BORBA; PENTEADO, 2010, p. 67).
}

Lembrando que os auxílios tecnológicos não se referem só às TICs, mas sim a todo arsenal de objetos, recursos, jogos, aplicativos e práticas atitudinais que eliminem as barreiras que impedem a aprendizagem de todos os nossos estudantes.

\section{ASPECTOS INCLUSIVOS RELACIONADOS À TECNOLOGIA ASSISTIVA}

O governo federal, juntamente com o MEC, estabeleceu a Política Nacional de Educação na Perspectiva da Educação Inclusiva e, sucessivamente, disponibilizou notas técnicas explicativas, orientações e serviços relacionados à educação inclusiva, onde todos precisam ser enxergados em suas necessidades e limitações (BRASIL, 2008). 
E, dentro dessa proposta inclusiva, remodelou novas bases de atendimento na educação especial para estudante com deficiência, Altas Habilidades e Superdotação e Transtornos Globais do Desenvolvimento. A educação especial é uma modalidade de ensino transversal que perpassa todos os níveis de ensino e que estabelece ações administrativas e pedagógicas que garantam o acesso de todos à educação de qualidade, permanência e acessibilidade para os estudantes públicoalvo da educação especial (BRASIL, 2008).

Segundo Bersch (2017), as redes públicas de educação possuem financiamento para compra de recursos de Tecnologias Assistivas por meio dos programas Salas de Recursos Multifuncionais, Escola Acessível do Plano de Ações Articuladas - PAR e do FUNDEB duplo. O Ministério da Educação introduziu o Serviço de Tecnologia Assistiva nas escolas.

Os diretores ou as secretarias municipais precisam estar atentos aos programas disponibilizados pelo MEC como, por exemplo, o PROGRAD "Escola Acessível" que disponibiliza verba diretamente na escola, na promoção da acessibilidade arquitetônica e compra de recursos de Tecnologia Assistiva.

No sistema - Plano de Ações Articuladas (PAR), "[...] poderão ainda solicitar salas de recursos multifuncionais e verbas específicas para compra de recursos de tecnologia destinados à complementação dos equipamentos já existentes nas salas de AEE" (BERSCH, 2017, p.18).

\section{CONSIDERAÇÕES FINAIS}

Dessa forma, compreendemos que a educação matemática e suas práticas pedagógicas precisam ir além dos cálculos e fórmulas aritméticas, ela precisa manter um diálogo crítico reflexivo com a sociedade e, sucessivamente, com a realidade da escola. A história, os grandes pensadores matemáticos, as grandes descobertas, tudo isso tem seu espaço, porém precisam fazer sentido e ter significado para os estudantes, pois assim conseguiram associar e fazer uma correspondência com a sua realidade, com a necessidade do conhecimento para a construção colaborativa.

Refletir a prática docente frente ao ensino e aprendizagem na educação matemática nos permite fazer uma analogia com todas as demais disciplinas, pois a BNCC postula a construção de uma nova cultura profissional, ou seja, é preciso que os professores tenham um novo olhar frente à construção de saberes.

Quando o professor compreende sua realidade, enxerga sua clientela, adequa conteúdos e, adaptando recursos, poderemos afirmar que esse professor compreende o real papel inclusivo entre o ato de aprender e ensinar. Nunca saberemos tudo, porém o desejo de sermos melhores e tornar o mundo de alguém melhor faz valer a pena estar nessa profissão, fazendo do processo educativo muito além do 
ato de transmitir conhecimento, mas sim fazer da escola uma ferramenta política de participação social e de transformação de realidades.

Precisamos enxergar no outro as marcas da história e compreender que todos nós, independente de sua condição física, sensorial ou de saúde, ajudamos a construir diariamente a realidade que nos cerca e que, querendo ou não, atinge a todos. Que saibamos olhar as potencialidades que cada um tem, somos mais quando somos juntos, independente de nossas limitações.

\section{REFERÊNCIAS}

AMARAL, L. A. Pensar a diferença/deficiência. Brasília: CORDE, 1994.

BERSCH, R. Tecnologia assistiva e educação inclusiva. In: Ensaios Pedagógicos, Brasília: SEESP/MEC, p. 89-94, 2006.

BERSCH, R. Introdução à tecnologia assistiva: assistiva, tecnologia e educação. Porto Alegre, Rio Grande do Sul, p. 1-20, 2017.

BICUDO, M. A. V. Pesquisa em Educação Matemática. Proposições, Campinas, v. 4, p. 18-23, 1993.

BORBA, M. C.; PENTEADO, M. G. Informática e educação matemática. 4. ed. Belo Horizonte: Autêntica, 2010.

BRASIL. Lei de Diretrizes e Bases da Educação Nacional. Lei n 9.394, de 20 de dezembro de 1996. Estabelece as Diretrizes e Bases da Educação Nacional. Brasília, DF,1996.

BRASIL. Constituição (1988). Constituição da República Federativa do Brasil. Brasília, DF: Senado Federal: Centro Gráfico, 1988.

BRASIL. Base Nacional Comum Curricular (BNCC). Consulta Pública. Brasília, MEC/CONSED/UNDIME, 2017.

BRASIL. Secretaria de Educação Especial - SEESP. Política Nacional de educação especial na perspectiva da educação inclusiva. 2008. Documento elaborado pelo Grupo de Trabalho nomeado pela Portaria $n^{\circ} 555 / 2007$, prorrogada pela Portaria $n^{\circ}$ 948/2007, entregue ao Ministro da Educação em 07 de janeiro de 2008.

BRASIL. Política Nacional da Educação na Perspectiva da Educação Especial. 2007. BRASIL. Convenção sobre os Direitos das Pessoas com Deficiência: Decreto Legislativo $n^{\circ}$ 186, de 09 de julho de 2008: Decreto $n^{\circ} 6.949$, de 25 de agosto de 2009. $4^{\mathrm{a}}$ Ed. Brasília: Secretaria de Direitos Humanos, 2010. 100p. 
FREIRE, P. Pedagogia da Esperança: um reencontro com a pedagogia do oprimido. Rio de Janeiro/RJ: Editora Paz e Terra, 1993.

JAVARONI, S. L.; ZAMPIERI, M. T. O Uso das TIC nas Práticas dos Professores de Matemática da Rede Básica de Ensino: o projeto Mapeamento e seus desdobramentos. Bolema, Rio Claro (SP), v. 29, n. 53, p. 998-1022, 2015.

MANTOAN, Maria Teresa Egler. Inclusão escolar: o que é? por quê? como fazer? 2. ed. São Paulo: Moderna, 2006.

MANTOAN. O direito de ser, sendo diferente, na escola: por uma escola das diferenças. Curso de Formação Continuada de Professores para o AEE. UFC/ SEESP/ UAB/MEC. 2010.

PONTE, J. P. Formação do professor de Matemática: perspectivas atuais. In: PONTE, J. P. (org.). Práticas profissionais dos professores de matemática. 1. ed. [S.I: s.n.], 2014.

PALACIOS, A. El modelo social de descapacitada: Orígenes, caracterización y plasmación en la ConvenciónInternacionalsobre los Derechos de las Personas con Discapacidad. Madrid: Cermi, 2008.

RADABAUGH, M. P. Study on the Financing of Assistive Technology Devices of Services for Individuals with Disabilities - A report to the president and the congress of the United State, National Council on Disability, 1993.

\section{BIOGRAFIA DAS AUTORAS}

MARIA INÊZ VASCONCELOS DA SILVA - Possui graduação em PEDAGOGIA pela UFMS/CEUL de Três Lagoas (Universidade Federal de Mato Grosso do Sul -1994), especialização em Educação Especial pela FIPAR (2004), Habilitação em Educação Especial (com ênfase em Deficiência Visual, pela instituição UNESP - Marília, 2009) e especialização em Neuropedagogia pela UNIJALES, 2010. Orientadora Educacional On-line área DV pela Unesp de Bauru - 2014/2015. Experiência enquanto Apoio Técnico da Educação Especial no município de Ilha Solteira/SP durante 7 anos (2010 a 2017). Em 2018, ingresso pelo SISU na graduação DIREITO/UFMS/CPTL (Campus de Três Lagoas-MS) - 2018/1922. Em 2019, ingresso no mestrado UNESP Campus de Ilha Solteira/SP em Ensino e Processos Formativos.

ANDREZZA SANTOS FLORES - Doutoranda pelo Programa de Pós-Graduação Strictu Sensu em Educação para a Ciência pela Faculdade de Ciências, Campus de Bauru, na linha de Pesquisa Fundamentos e modelos psicopedagógicos no Ensino de 
Ciências e Matemática. Mestre pelo Programa Multidisciplinar Interunidades de Pós Graduação Strictu Sensu: Ensino e Processos Formativos (UNESP São José do Rio Preto/llha Solteira e Jaboticabal). Graduada no curso de Licenciatura e Bacharelado em Ciências Biológicas pela Universidade Estadual Paulista "Júlio de Mesquita Filho"UNESP, Campus de Ilha Solteira.

Data de recebimento: 01/09/2020

Data de aprovação: 23/10/2020 